\title{
Nonarteritic anterior ischaemic optic neuropathy in Addison's disease
}

\begin{abstract}
Purpose To report three cases of Nonarteritic anterior ischaemic optic neuropathy

(NAAION) in patients with Addison's disease Methods We present a retrospective review of patients presenting with NAAION with underlying Addison's disease.

Results Three eyes of two young patients presented with NAAION. Both patients had underlying Addison's disease with episodes of prolonged hypotension.

Conclusion To our knowledge, this is the first published report of NAAION associated with Addison's disease. As hypotension may be one of the few situations, in which NAAION may be treatable and the visual loss reversible, it is important to recognize and treat sustained episodes of hypotension in these individuals. Eye (2010) 24, 1618-1620; doi:10.1038/eye.2010.101; published online 30 July 2010
\end{abstract}

Keywords: non arteritic anterior ischaemic optic neuropathy; Addison's disease; hypotension

\section{Introduction}

Nonarteritic anterior ischaemic optic neuropathy (NAAION) is the most common

Bristol Eye Hospital, Bristol, UK

Correspondence: S Haider, University Hospital North Durham, North Road, Durham, DH1 5TW, UK Tel: 01388455181; Fax: 01913332251. E-mail: drsajjadhaider@ yahoo.co.uk

Received: 8 March 2010 Accepted in revised form: 18 May 2010 Published online: 30 July 2010 cause of acute optic neuropathy in older age groups. It is characterized by visual loss associated with optic disc swelling with subsequent varying degrees of optic atrophy. The incidence of NAAION is estimated at 2.3-10.3 per $100000 .^{1,2}$

Chronic hypoperfusion of small end-arterial blood vessels that supply the optic nerve head may predispose to NAAION. It has been hypothesized that if an optic nerve head has been rendered vulnerable to ischaemia by various predisposing factors (such as aging, hypertension, and arteriosclerosis), nocturnal hypotension may act as the final insult leading to NAAION. ${ }^{3,4}$
AH Ross, S Haider and CC Bailey

\section{Case 1}

A 46-year-old gentleman presented to eye casualty with sudden onset of visual loss in his left eye, describing a patch of field loss inferiorly.

On further questioning, he reported suffering from Addison's disease. He was diagnosed 10 years earlier when a short synacthen test failed to demonstrate an incremental rise of cortisol of $>200 \mathrm{nmol} / 1$ and the peak cortisol was $<50 \mathrm{nmol} / 1$ at $30 \mathrm{~min}$. He was being treated with fludrocortisone and hydrocortisone therapy, and had previously experienced subjective hypotensive episodes.

On examination, he read 6/4 in both eyes. His anterior segments were normal with normal intraocular pressures. However, fundoscopy demonstrated a swollen hyperaemic left optic nerve head particularly on the nasal side. The right optic nerve was normal in appearance. $\mathrm{He}$ had an inferior altitudinal visual field defect on Goldmann visual field testing (Figure 1).

Although his lying and standing blood pressure were 130/70 when tested in the eye department, the patient reported awareness of hypotensive episodes in the preceding weeks. Haematological and biochemical blood tests were normal. $24 \mathrm{~h}$ blood pressure monitoring revealed sustained hypotension lasting $\sim 7 \mathrm{~h}$ between midnight and morning (minimum systolic 98 , minimum diastolic 54 ).

A diagnosis of NAAION was made secondary to hypotensive episodes related to his Addison's disease.

Case 2

A 57-year-old woman presented with right visual field disturbance of 2 weeks duration. She was known to have type II autoimmune polyendocrinopathy, Addison's disease, hypothyroidism, and pernicious anaemia. Addison's disease had previously been 


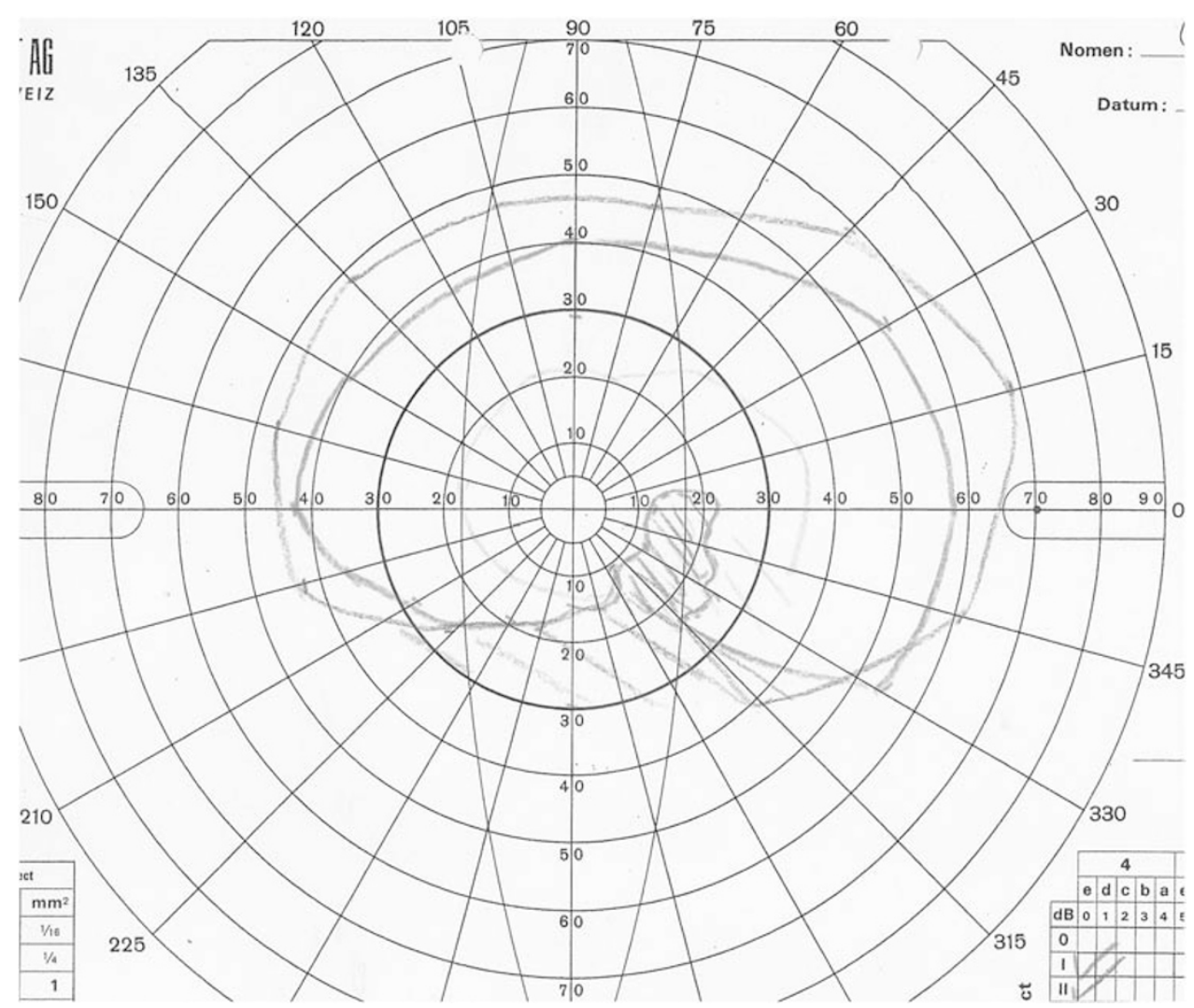

Figure 1 Goldmann visual field test demonstrating an inferior altitudinal visual field defect.

confirmed with a short synacthen test (peak cortisol $<50 \mathrm{nmol} / 1$ at $30 \mathrm{~min}$ ). She was receiving hydrocortisone, thyroxine, and hydroxycobalamine injections. On examination, she had a visual acuity of $6 / 36$ in right and 6/5 in left. There was no past ocular history or relevant family history. She had a right light brightness perception defect, afferent pupil defect, and right optic disc swelling. A goldmann visual field demonstrated an inferior altitudinal defect. Magnetic resonance imaging showed no abnormality, although electrodiagnostic testing demonstrated a conduction defect in the right eye. The patient was diagnosed with NAAION and managed conservatively.

The patient re-presented 2 years later with sudden deterioration of vision in her left eye of 3-4 weeks duration. Visual acuity was 6/12 right and 6/30 left, improving with pinhole to $6 / 24$. She had a left afferent pupil defect and complete loss of colour vision. Left optic disc margins were blurred (Figure 2). $24 \mathrm{~h}$ blood pressure monitoring revealed sustained hypotension lasting $\sim 10 \mathrm{~h}$ between late evening and morning (minimum systolic 93, minimum diastolic 52).

Both patients were subsequently managed in conjunction with the endocrinologists to achieve tighter blood pressure control.

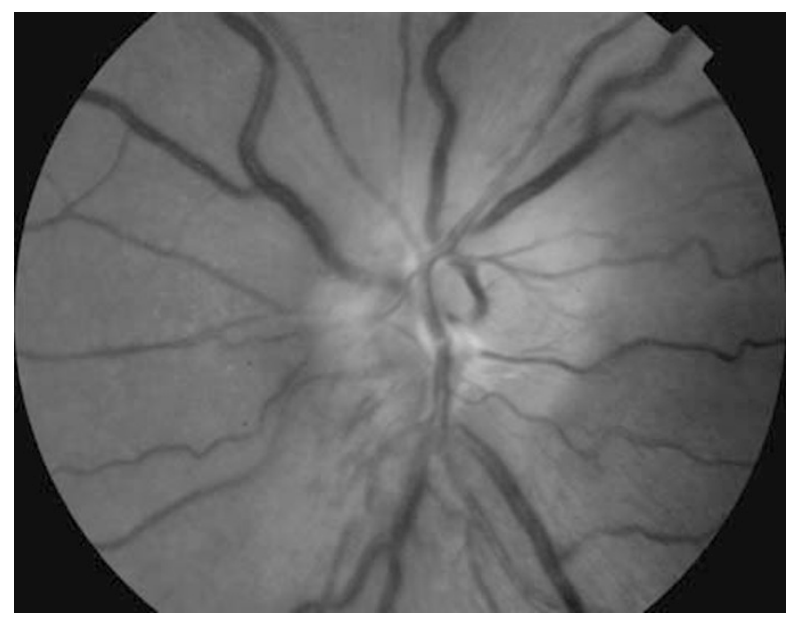

Figure 2 Red-free fundal photograph demonstrating blurred left optic disc margins.

\section{Discussion}

Addison's disease or primary adrenal insufficiency was first described by Thomas Addison in 1849 secondary to adrenal tuberculosis. ${ }^{5}$ It is a rare syndrome resulting from adrenocortical (glucocorticoid and mineralocorticoid) insufficiency. It usually presents with 
an insidious onset with symptoms, such as malaise, anorexia, diarrhoea, weight loss, and back pain, as well as cutaneous manifestations, usually in the form of hyperpigmentation. ${ }^{6}$

Routine investigation may demonstrate hyperkalaemia, hyponatraemia, hypoglycaemia, eosinophilia, lymphocytosis, and possible metabolic acidosis.

Investigation using basal plasma cortisol levels is an insensitive test and diagnosis is usually by the short and long ACTH stimulation test. The short test analyses plasma cortisol pre- and post- $250 \mu \mathrm{g}$ of synthetic ACTH (tetracosactide) and if the plasma cortisol exceeds $140 \mathrm{nmol} / 1$ initially and is $>500 \mathrm{nmol} / 1$ after $1 \mathrm{~h}$, adrenal failure can be excluded. The long test differentiates between primary adrenal failure and secondary adrenocortical failure.

There are many risk factors that have been associated with NAAION. Diabetes mellitus represents a major risk factor for developing NAAION. Jacobson et $a l^{7}$ demonstrated that diabetes was associated with an odds ratio of 2.7 for developing future NAAION. The role of hypertension as an independent risk factor remains controversial with conflicting opinions, but may be more important in younger patients.

Although NAAION usually occurs spontaneously, it is known to occur following acute hypotension. Conolly et $a l^{8}$ reported three cases of NAAION secondary to hypotension episodes related to haemodialysis, rapid correction of malignant hypertension and systemic hypovolaemia.

Hayreh et $\mathrm{al}^{9}$ carried out a cohort study looking at the natural history of the visual outcome in NAAION in 386 eyes. The group concluded that $50 \%$ of the eyes presented with normal visual acuity, and hence, the presence of normal visual acuity does not rule out NAAION. The study also concluded that visual acuity and visual fields showed improvement or further deterioration up to 6 months with no subsequent significant change.

Landau et al $^{10}$ looked at the parameters of ambulatory diurnal blood pressure in patients with NAAION, concluding that this latter group of patients consistently had a lower mean blood pressure than control subjects. In addition, it was noted that these patients had a lag in the usual rise in blood pressure in the morning to meet increasing demands for perfusion. To our knowledge, this is the first published report of NAAION associated with Addison's disease. As hypotension may also be one of the few situations where NAAION may be treatable and the visual loss reversible, it is important to recognize
Summary

What was known before

- Nonarteritic anterior ischaemic optic neuropathy is the most common cause of acute optic neuropathy in older age groups. There are a variety of risk factors including diabetes, hypertension, and hypotension.

What this study adds

- Hypotensive episodes secondary to Addison's disease are a potential reversible cause of nonarteritic anterior ischaemic optic neuropathy (NAAION). It is important to carry out a thorough medical history of all patients presenting NAAION.

and treat sustained episodes of hypotension in these individuals.

\section{Conflict of interest}

The authors declare no conflict of interest.

\section{References}

1 Hattenhauer MG, Leavitt JA, Hodge DO, Grill R, Gray DT. Incidence of nonarteritic anterior ischemic optic neuropathy. Am J Ophthalmol 1997; 123: 103-107.

2 Johnson LN, Arnold AC. Incidence of nonarteritic and arteritic anterior ischemic optic neuropathy. Populationbased study in the state of Missouri and Los Angeles County, California. J Neuroophthalmol 1994; 14: 38-44.

3 Hayreh SS, Zimmerman MB, Podhajsky P, Alward WL. Nonarteritic anterior ischemic optic neuropathy: role of nocturnal arterial hypotension. Arch Ophthalmol 1997; 115(7): 942-945.

4 Hayreh S, Zimmerman M, Podhajsky P, Alward WL. Nocturnal arterial hypotension and its role in optic nerve head and ocular ischemic disorders. Am J Ophthalmol 1994; 117: 603-624.

5 Thomas Addison. On The Constitutional And Local Effects Of Disease Of The Supra-Renal Capsules. Samuel Highley: London, 1855.

6 Nieman LK, Chanco Turner ML. Addison's disease. Clin Dermatol 2006; 24(4): 276-280. Review.

7 Jacobson DM, Vierkant RA, Belongia EA. Nonarteritic anterior ischemic optic neuropathy. A case-control study of potential risk factors. Arch Ophthalmol 1997; 115: 1403-1407.

8 Conolly S, Gordon K, Horton J. Salvage of vision after hypotension induced ischemic optic neuropathy. Am J Ophthalmol 1994; 117: 235-242.

9 Hayreh SS, Zimmerman MB. Nonarteritic anterior ischemic optic neuropathy: natural history of visual outcome. Ophthalmology 2008; 115(2): 298-305.e2. Epub 2007 Aug 15.

10 Landau K, Winterkorn JM, Mailloux LU, Vetter W, Napolitano B. 24-hour blood pressure monitoring in patients with anterior ischemic optic neuropathy. Arch Ophthalmol 1996; 114(5): 570-575. 